\title{
Ethylene Glycol Regeneration Plan: A Systematic Approach to Troubleshoot the Common Problems
}

\author{
Md. Emdadul Haque \\ Jalalabad Gas Plant, Chevron Bangladesh
}

\begin{abstract}
Mono Ethylene Glycol (MEG) is used primarily at low-temperature processing plant for extracting natural gas liquids. Typically a physical process plant comprises with gas dehydration system which allows for physical separation of water saturated gas by simple dew point depression and water condensation brought about by chilling from cross exchange with propane refrigerant. The resultant wet gas is prevented from freezing by injection of liquid desiccants to inhibit hydrate formation. The resulting dehydrated gas stream will have a dew point preciously equal to the saturated water volume of the gas at its coolest temperature.

Mono Ethylene Glycol has been chosen as hydrate inhibitor because of its low volatility, low toxicity, low flammability, good thermodynamic behavior, and simple proven technology requirement and availability. But it has two common characteristic problems in regeneration plant that is fouling of equipment by iron carbonate, $\mathrm{Ca}^{+2} / \mathrm{Mg}^{+2}$ salt deposits and cross contamination of MEG and condensate contamination. MEG in condensate causes condensate specification problems, fouling of condensate stabilization equipment and contamination of wastewater streams. Condensate in MEG causes stripping effect due to condensate vaporization, lower operating temperature, higher MEG purities, and contamination of wastewater streams from MEG Regeneration system and burping of column due to condensate buildup. Another common problem is glycol losses due to carryover with dehydrated gas and which finally accumulates in pipelines and causes corrosion. Other reasons of glycol losses are higher column temperature, foaming, leaks at pump or pipe fittings, operated with excessive gas flow rates and rapid changes in gas flow rates. Column Flooding occurred if feed glycol circulation rate exceeded design limit and it does not allow proper separation of glycol and water separator and much glycol losses through vent line.
\end{abstract}

This paper presents an experimental study of glycol losses. Effort has been made to investigate the causes and the study suggests some mitigation plans. Current study suggests the efficiency of the dehydration process depends on a large extent on the cleanliness of the glycol and the regular monitoring of glycol parameters such as glycol concentration, hydrocarbon content, salt content, solids content, $\mathrm{pH}$ stabilization, iron content, foaming tendency etc. Losses due to vaporization from reboiler can be minimized by adjusting operating parameters. By developing monitoring procedure and periodic maintenance about $90 \%$ operating problems of Glycol Regeneration Plant can be reduced.

Key Words: Mono Ethylene Glycol (MEG), Glycol Loss, Contamination

\section{Introduction}

Jalalabad Gas Field is located in Block 13, northeastern part of Bangladesh. It is a physical processing plant started its production on $21^{\text {st }}$ March 1999 with initial capacity of 125 MMSCFD. Later on its capacity increased to 230 MMSCFD by installing a bypass line to allow a side stream of saturated gas to blend with dehydrated gas such that combined stream have a water dew point below $7 \mathrm{lb} / \mathrm{mmscf}$. Initially its gas processing technology was methanol dehydration system and it was converted into Ethylene Glycol Injection system on $10^{\text {th }}$ November 2005. It has four producing well connected to HP and Test header via 12" and 8" pipelines. Gas \& Condensate Separation, Gas dehydration, water and hydrocarbon dew point control, condensate stabilization is the main function of this processing plant.

\footnotetext{
* Corresponding Author: Md. Emdadul Haque

Email: emdad@chevron.com; haque.md.emdadul@gmail.com
}

After conversion from methanol to Ethylene Glycol System, its Glycol Regeneration Plant faced some problems such as glycol loss, scaling/fouling problem on regeneration equipment, condensate carryover to reboiler, foaming problem and leakage from injection pump seal. This paper deals with how these problems can be minimized by analyzing plant operating data, adjusting process variables, laboratory analysis and improved maintenance program.

\section{Chemistry of Ethylene Glycol Dehydration Process}

Ethylene Glycols are straight chain aliphatic compounds terminated at each end by a hydroxyl group. Ethylene Glycol is manufactured by the hydration of ethylene oxide. 
Table-1: Ethylene Glycol Properties

\begin{tabular}{|l|c|}
\hline Formula & $\mathrm{C}_{2} \mathrm{H}_{6} \mathrm{O}_{2}$ \\
\hline Molecular Weight & 62.1 \\
\hline Boiling Point, ${ }^{\circ} \mathrm{F}$ & 387.1 \\
\hline Flash Point, ${ }^{\circ} \mathrm{F}$ & 240 \\
\hline Fire Point, ${ }^{\circ} \mathrm{F}$ & 245 \\
\hline Freezing Point, ${ }^{\circ} \mathrm{F}$ & 8 \\
\hline Vapor Pressure, $\mathrm{mm} \mathrm{Hg}$ & 0.12 \\
\hline Density, g/cc & 1.11 \\
\hline Specific Heat, BTU/lb- ${ }^{\circ} \mathrm{F}$ & 0.58 \\
\hline Viscosity, cp & 16.5 \\
\hline Refractive Index & 1.43 \\
\hline
\end{tabular}

Among other glycols Ethylene Glycol (EG) is most popular because of its lower cost, lower viscosity and lower solubility in liquid hydrocarbons. The viscosities of EG and its aqueous solutions increase significantly as temperature decreases and this must be allowed for in the rating of refrigeration plant exchangers and chillers. Solubility of EG in the liquid hydrocarbon phase is extremely small. ${ }^{1}$

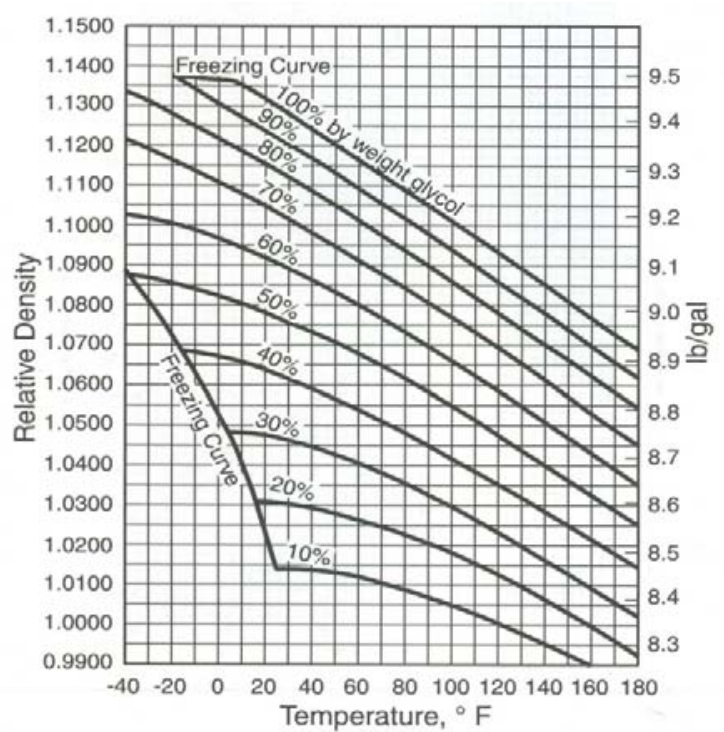

Fig. 1. Freezing Curve of Ethylene Glycol

\section{Ethylene Glycol Regeneration Process \& Problems}

Lean EG is injected through injection nozzle with water saturated gas at tube side of exchanger and chiller. Lean EG absorbs water from and be settled in Low Temperature Separator boot as rich EG. Rich EG then enters the regeneration system through reflux coil in the top of stripper column, where it is preheated. Rich EG then flows to plate-frame exchanger to heat exchange with warmer lean EG, before entering the Flash Separator. In the Flash Separator, hydrocarbon is separated from EG-Water mixture. Rich EG then flows through particulate filter and carbon filter where contaminants are removed and hydrocarbons are adsorbed. After being filtered, the rich glycol is fed into the reboiler for regeneration. In the reboiler, rich glycol enters at the top of the stripper column and flows down through a packed bed to flash off water and residual hydrocarbons. The glycol then flows down to the main body of the reboiler where rich EG becomes lean. The Lean EG flows through the plate-frame exchanger where it is cooled before entering the Glycol Accumulator. The Lean EG is then re-injected to exchanger and chiller by injection pump and completes the close loop. ${ }^{[2]}$ Glycol circulation rate is 4 GPM and required concentration is $82 \%$. Stripping gas line was introduced after startup of the plant as it was not in original design. Very often plant upset occurred and the following problems were observed:

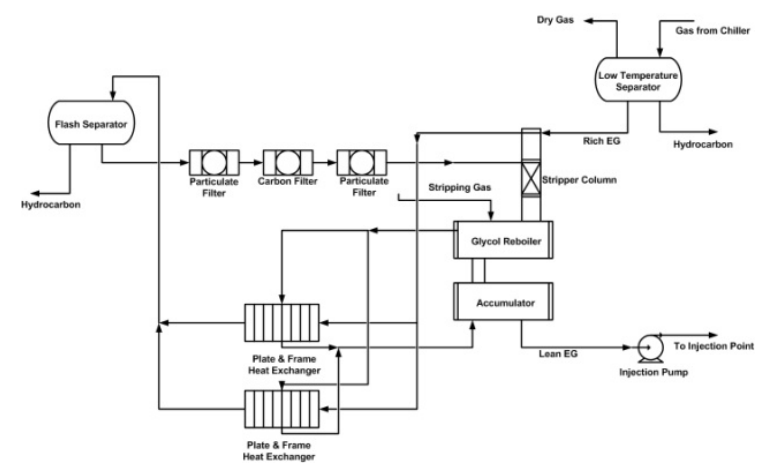

Fig. 2. Process Flow Chart of EG Regeneration Plant

\subsection{Glycol Loss}

Most of the common problem was glycol losses due to vaporization, carryover with gas \& condensate, low $\mathrm{pH}$, improper concentration, rapid gas flow fluctuation. At normal operating condition glycol consumption is 0.23 bpd while at unstable condition glycol consumption rises to 2.0 bpd. Fig.-3 and Fig.-4 shows the scenario of glycol consumption and a comparison with normal operating condition.

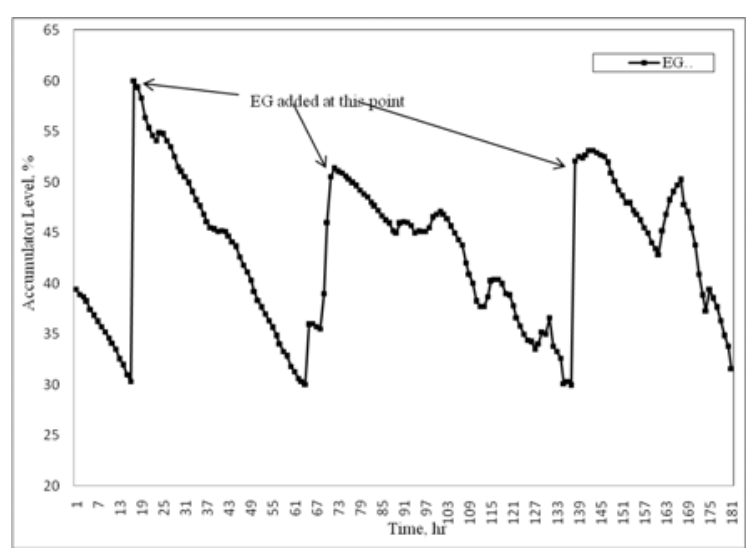

Fig. 3. EG Consumption Trend 
In Fig.3, the peak points shows that glycol was added as a makeup from storage tank to Glycol Accumulator and trends shows the consumption profile.

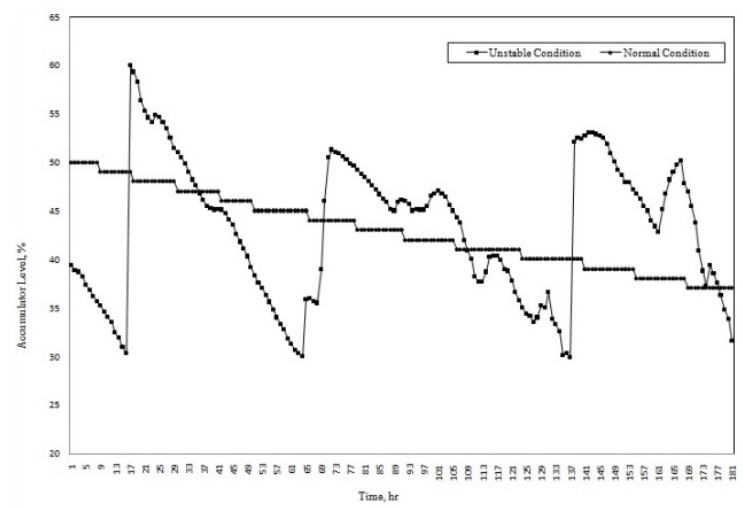

Fig. 4. Comparison with normal operating condition

Fig.4 shows the comparison of glycol consumption at normal operation and upset condition.

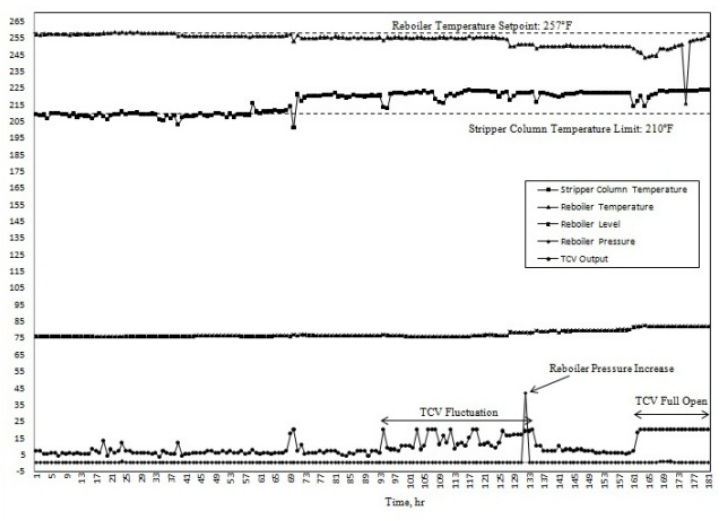

Fig. 5. Reboiler Performance

Fig.5 represents the overall reboiler performance at unstable condition. It shows that stripper column temperature increased to $225^{\circ} \mathrm{F}$ where normal limit is $210 \sim 212^{\circ} \mathrm{F}$ which is the boiling point of water. When this temperature reached to $225^{\circ} \mathrm{F}$ then some glycol vapor was allowed going with water vapor. Reboiler operating temperature was $257^{\circ} \mathrm{F}$ which is below EG decomposition temperature $\left(325^{\circ} \mathrm{F}\right)$ and it dropped down to $243^{\circ} \mathrm{F}$ which leads to lower concentration of Lean EG. At the same time Temperature Control Valve (TCV) was fluctuating and tried to full open to enter more fuel gas to maintain the Reboiler temperature but it failed to do so and as a result Reboiler pressure increased to $1.75 \mathrm{psig}$ which is harmful for atmospheric vessel. Any fluctuation of TCV leads to unsteady temperature of reboiler and stripper column.

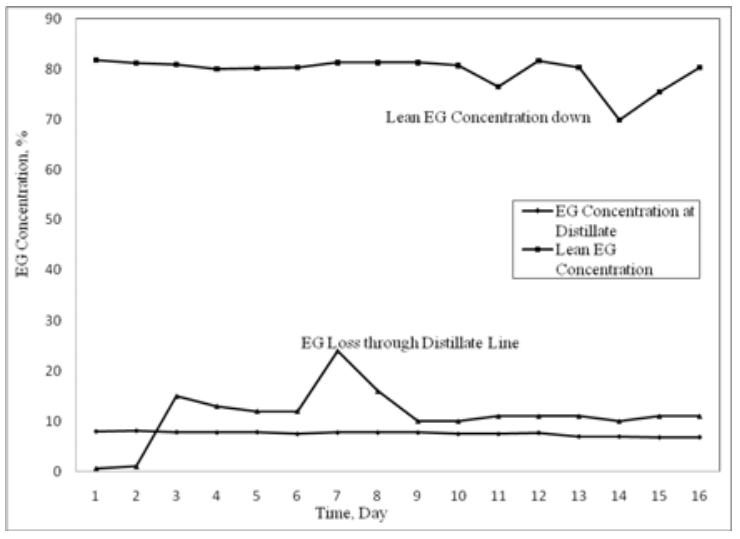

Fig. 6. EG Concentration and $\mathrm{pH}$ Profile at Reboiler and Distillate

Fig.6 shows the concentration profile of Lean EG at reboiler and at distillate collection vessel where maximum $25 \% \mathrm{EG}$ was found.

\subsection{Scaling \& Fouling}

Scaling \& fouling is very common in glycol system. It can be minimized by maintaining quality of glycol.

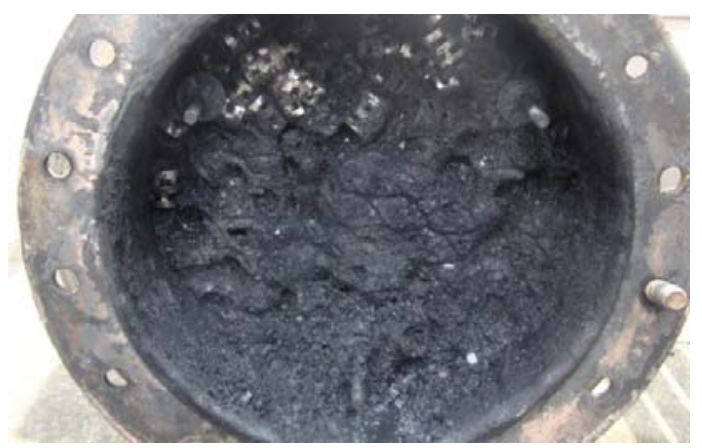

Fig. 7. Blocked Stripper Column due to Fouling

For inspection purpose glycol reboiler and stripper column were opened and stripper column was found to be almost block and channeling occured in one side. Fig.-7 shows the scenario of stripper column.

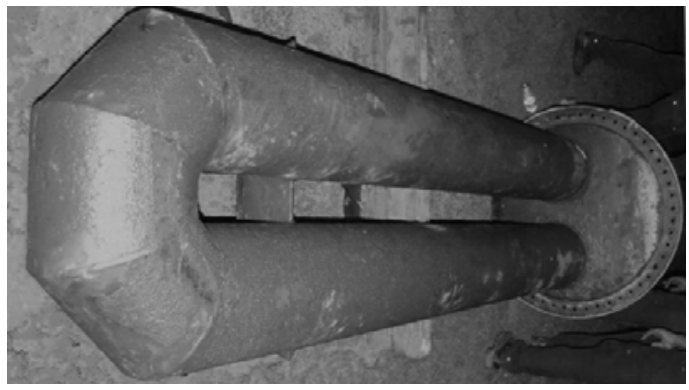

Fig. 8. Scale on Reboiler Fire tube 


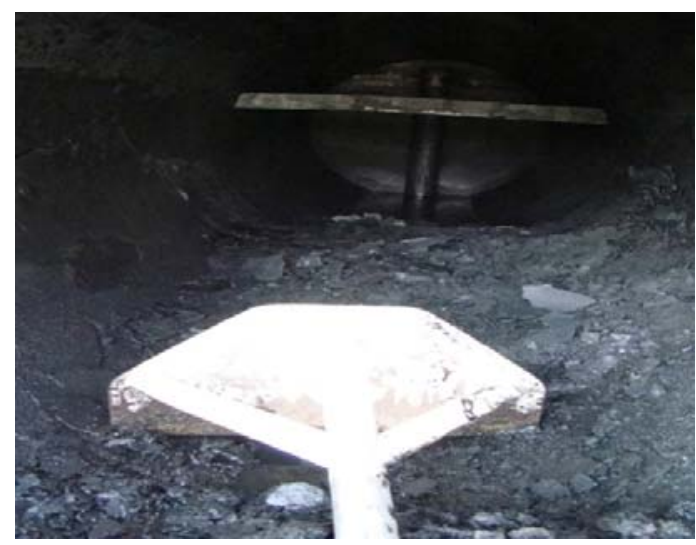

Fig. 9. Reboiler inside condition

Fig.-8 and 9 shows the condition of fire tube of reboiler and inside condition of reboiler respectively. Thick scale deposited on all part of fire tube and Reboiler inner wall.

Table 2. Solid Sample analysis of Fire Tube and Reboiler

\begin{tabular}{|c|c|c|c|}
\hline Element & Unit & $\begin{array}{l}\text { Fire } \\
\text { Tube }\end{array}$ & $\begin{array}{l}\text { Stripper } \\
\text { Column } \\
\end{array}$ \\
\hline Aluminium as $\mathrm{Al}$ & ppm & 0.08 & 0.08 \\
\hline Antimony as $\mathrm{Sb}$ & ppm & 0.00 & 0.00 \\
\hline Arsenic as As & ppm & 0.00 & 0.00 \\
\hline Boron as B & ppm & 0.01 & 0.02 \\
\hline Barium as $\mathrm{Ba}$ & ppm & 0.01 & 0.02 \\
\hline Bismuth as $\mathrm{Bi}$ & $\mathrm{ppm}$ & 0.11 & 0.11 \\
\hline Calcium as $\mathrm{Ca}$ & ppm & 0.11 & 0.27 \\
\hline Cadmium as $\mathrm{Cd}$ & $\mathrm{ppm}$ & 0.03 & 0.03 \\
\hline Cobalt as $\mathrm{Co}$ & ppm & 0.00 & 0.00 \\
\hline Chromium as $\mathrm{Cr}$ & $\mathrm{ppm}$ & 0.12 & 0.16 \\
\hline Cupper as $\mathrm{Cu}$ & $\mathrm{ppm}$ & 0.03 & 0.03 \\
\hline Iron as $\mathrm{Fe}$ & $\mathrm{ppm}$ & 109.40 & 108.80 \\
\hline Magnesium as Mg & $\mathrm{ppm}$ & 0.18 & 0.15 \\
\hline Manganese as Mn & ppm & 1.79 & 3.79 \\
\hline Mercury as $\mathrm{Hg}$ & $\mathrm{ppm}$ & 0.16 & 0.10 \\
\hline $\begin{array}{l}\text { Molybdenum as } \\
\text { Mo }\end{array}$ & ppm & 0.00 & 0.00 \\
\hline Nickel as Ni & $\mathrm{ppm}$ & 0.00 & 0.01 \\
\hline Lead as $\mathrm{Pb}$ & ppm & 0.02 & 0.02 \\
\hline Silicon as $\mathrm{Si}$ & $\mathrm{ppm}$ & 1.54 & 1.20 \\
\hline Silver as Ag & ppm & 0.00 & 0.00 \\
\hline Selenium as $\mathrm{Se}$ & $\mathrm{ppm}$ & 0.00 & 0.00 \\
\hline Thallium as $\mathrm{Tl}$ & ppm & 0.00 & 0.00 \\
\hline Titanium as $\mathrm{Ti}$ & $\mathrm{ppm}$ & 0.02 & 0.02 \\
\hline Vanadium as V & ppm & 0.00 & 0.00 \\
\hline Zinc as $\mathrm{Zn}$ & ppm & 0.42 & 0.63 \\
\hline
\end{tabular}

Laboratory analysis report of collected scale materials sample from fire tube and reboiler shows that iron is the main element. Table-2 shows the analysis report. Source of iron is produced water that comes into contact at exchanger where Lean EG is injected and water used for preparation of $82 \%$ EG solution. Scale is formed as carbonate and bi-carbonate of $\mathrm{Fe}, \mathrm{Ca}$ and $\mathrm{Mg}$ which also depends on $\mathrm{pH}$ of Lean EG. The reaction is:

$\mathrm{CO}_{2}+\mathrm{OH}^{-\mathrm{pH} \sim 7.0} \leftrightarrow \mathrm{HCO}_{3}^{-\mathrm{pH} \sim 8.5} \leftrightarrow \mathrm{CO}_{3}^{-2}+\mathrm{H}_{2} \mathrm{O}$ $\rightarrow$ Insoluble carbonate $(\mathrm{Fe} / \mathrm{Ca} / \mathrm{Mg})$

\subsection{Hydrocarbon Carryover}

An accumulation of solid particles and hydrocarbon very often forms sludge in the glycol solution at low $\mathrm{pH}$. This sludge is suspended in the circulating glycol and, over a period of time, the accumulation becomes large enough to settle down. This action results in the formation of a black, sticky and abrasive gum which can cause erosion of pumps, valves, and other equipment. This sludge becomes very hard and brittle when it deposits onto stripper packing and other places in the circulating system. It was observed that hydrocarbon was carried over with EG due to improper separation at Flash Separator. There is two particulate filter and one carbon filter at inlet line of reboiler. As a result sludge formed when Lean EG $\mathrm{pH}$ was low and this sludge blocked the filters. As a result, filter media need to change frequently. Another problem was found that it caused foaming which is another factor of loosing EG.

\subsection{Pump Seal Leakage}

Plunger type reciprocating pump is used as injection pump and plunger seal leakage was found to be a frequent problem which leads to EG loss.

\section{Mitigation Technique \& Discussion}

Most of the problems of dehydration and regeneration process can be minimized by taking care of glycol solution. A good quality glycol can give us high efficiency and uninterrupted plant operation. Following control measures were taken to mitigate the aforesaid problems and a brief explanation of taking these control measures are given below:

\subsection{Stripping Gas}

Stripping gas helps to achieve high glycol concentration which cannot be obtained by normal regeneration. Hot gas has an affinity for water. So gas is bubbled through the hot glycol in the reboiler to remove water that was not cooked out. This gas may be put directly into the reboiler, or it may be added to the storage tank, so that it can be percolated through a packed column between the two vessels. The dry glycol spills downward by gravity over the packing, while the gas goes upward, removing even more water. By this method, the glycol 
may be purified to almost $100 \%$. This method has another advantage. It prevents air from coming into contact with the dry glycol in the storage tank thus preventing oxidation of the glycol. Oxygen in the air will decompose glycol to some extent and cause corrosion in the system.

Sometimes it is found that stripping gas blocked due to liquid trapped inside the tubing and stripping gas regulator may blocked or malfunctioning. We found our stripping gas is blocked due to regulator blockage.

\subsection{Reflux Ratio Control}

By controlling reflux ratio stripper column temperature can be controlled which is necessary to meet water boiling point. This can be achieved by operating stripper column bypass valve or by installing a threeway valve with temperature controller which is a better solution. As a three-way valve was not available it was controlled by operating stripper column bypass valve and found $25 \%$ reflux is enough for good control by trial \& error process

\section{3. pH Control}

$\mathrm{pH}$ is a measure of the acid content of the glycol and is an indication of glycol degradation taking place. The desired $\mathrm{pH}$ of the solution is 7.4 to 8.5. If proper measures are not taken, the $\mathrm{pH}$ will continue to decrease as the unit operates. The equipment corrosion rate increases rapidly with a decrease in the glycol $\mathrm{pH}$. Organic acids resulting from the oxidation of glycol, thermal decomposition products and acid gases picked up from the gas stream are the most troublesome corrosive compounds. Therefore, the glycol $\mathrm{pH}$ should be checked periodically.

Produced water $\mathrm{pH}$ is $6 \sim 6.5$, so when EG absorbed this water its $\mathrm{pH}$ went down and day by day glycol's $\mathrm{pH}$ dropped down. Ethanolamine (Di-ethanolamine, Triethanolamine) are commonly used to increase $\mathrm{pH}$.

\subsection{Salt Contamination}

Salt deposits accelerate equipment corrosion, reduce heat transfer in the regenerator tubes, and alter specific gravity. This troublesome compound cannot be removed with normal regeneration.

The heat transfer rate of the reboiler is reduced by deposits of coke, tarry compounds and/or salt deposits on the tubes. Ultimately, this can cause tube failure. Additionally, these contaminants will decompose the glycol. An analysis of the glycol shows the amount of these contaminants. Salt deposits can also be detected by routine inspection of the tube bundle during periodic shutdowns. The coke and tarry compound present in the circulating solution may be removed by good filtration.
Fig. 8 is the example of this problem. Now it is planned to clean reboiler and replace packing materials annually and this technique is giving good results.

\subsection{Increase Separation Efficiency}

Hydrocarbon in glycol indicates that separation is not adequate at Flash Separator. Without changing any equipment we can do it by increasing retention time in the separator. To increase retention time we can increase Rich EG level at Flash Separator. Carbon filter is the second step to remove hydrocarbon from glycol. Periodic check at carbon filter outlet can give better solution. Slightly brownish color indicates that carbon filter is working otherwise carbon filter should be changed.

\subsection{Foam Control}

Foaming can increase glycol losses and reduce the plant capacity. Foaming also causes poor contact between the gas and the glycol solution; therefore, the drying efficiency is decreased. Glycol does not foam by itself, rather as a result of impurities, particularly at relatively low temperatures. Some foam promoters are hydrocarbon liquids, corrosion inhibitors, salt and finely divided suspended solids.

Excessive turbulence and high liquid-to-vapor contacting velocities will usually cause the glycol solution to foam. This condition can also be caused by mechanical or chemical troubles. The best cure for foaming problem is proper care of the glycol solution. The most important measures in the program are effective gas cleaning ahead of the glycol system and good filtration of the circulating solution.

Dirty packing, caused by deposits of salt and/ or tarry hydrocarbons, will also cause solution foaming in the still and increase glycol losses. Therefore, the packing should be cleaned or replaced when plugging occurs. Fig.-7 is the example of dirty packing and it is planned to clean or replace annually.

Besides these, analysis of glycol solution is essential for smooth plant operation. It also enables the operator to evaluate the plant performance and make operating changes to get a maximum drying efficiency. For analysis of glycol sample, at first it is needed to be checked visually to identify contaminants. A finely divided black precipitate may indicate the presence of iron corrosion products; a black, viscous solution may contain heavy hydrocarbons; the characteristic odor of decomposed glycol (a sweet, aromatic smell) usually indicates thermal degradation; a two-phase liquid sample usually indicates that the glycol solution is heavily contaminated with hydrocarbons. The visual conclusions should then be supported by chemical analysis. Some of the routine tests which can be run are $\mathrm{pH}$, salt analysis, hydrocarbon determination, solids 
content, foam test, specific gravity, and water content. These analyses usually provide sufficient information to establish the condition of glycol solution. Proper pump maintenance will reduce operating costs. When the pump is not working, the whole plant must be shut down because the gas cannot be dried efficiently without a good continuous flow of glycol in the Contactor Tower. Therefore, there must be one standby pump permanently.

A constant gas flow at dehydration system is needed to be maintained. Lower Glycol concentration caused hydrate formation at exchanger tubes.

\section{Recommendations}

Besides monitoring and periodic maintenance program this paper has made some recommendations. They are as follows:

- Need to modify demister pad and internals at gas outlet line of Low Temperature Separator so that EG carried over with gas stream during high velocity can be minimized.

- Need to increase separation capacity of Flash Separator.

- Should use soft water for preparation of EG solution instead of utility water due to $\mathrm{Fe}, \mathrm{Mg}$, $\mathrm{Ca}$ content. By employing natural aeration and particulate filtration, system can give improved results.

- $\quad$ EG transferring system should be oxygen free.

- EG circulation rate should be variable rate so that it can be adjusted while low concentration is observed and hydrate formation at exchanger tube side and water dew point can be controlled in better way.

\section{Conclusion}

The problems discussed here are very common in Ethylene Glycol Regeneration Plant. Among the problems discussed here, any one of them can increase production cost in a large extent. To optimize the plant there is no way except taking good care of glycols and routine maintenance of equipments. Glycol losses due to rapid flow fluctuation and carried over due to high velocity is hard to control, except this all other problems can be minimized.

\section{References}

1. Engineering Data Book, Gas Processors Suppliers Association, $12^{\text {th }}$ edition, Volume 2, 2004.

2. Process Description and Control Narrative, Jalalabad Gas Plant, Chevron Bangladesh, Volume 1, Revision 2, 2005.

3. Campbell, John M., Gas Conditioning and Processing, edited by Hubbard, Robert A., $8^{\text {th }}$ edition, John M. Campbell and Company, Volume 2, February 2004.

4. MEG Regeneration Technical Meeting Presentation, Jiang, Victoria \& Tasmania Section, SPE, June 2009.

5. Smart, John S.; Robert, Randy; Possible Glycol Corrosion in Nominally Dry Gas Pipelines, $61^{\text {st }}$ Annual Conference \& Exposition on Corrosion, SPE Paper No. 06442.

6. Kumar, Sonjoy, Gas Production Engineering, Gulf Publishing Company, Volume 4, 1987.

7. Olsen, Stein; Corrosion Control by Inhibition, Environmental Aspects and $\mathrm{pH}$ Control, $61^{\text {st }}$ Annual Conference \& Exposition on Corrosion, SPE Paper No. 06683. 